\title{
Comparison of the Performance of MR-deDuster with Other Conventional Cyclones
}

(Perbandingan Prestasi MR-deDuster dengan Siklon Konvensional Lain)

\author{
M. RASHID*, N. HUDA, H. NORELYZA \& N. HASYIMAH
}

\begin{abstract}
A new type of cyclone design configuration called MR-deDuster, which contains multi cyclone, has been developed. A theoretical study had been carried out to evaluate and predict the performance of a MR-deDuster. In this paper, a comparative study was done to investigate the performance of MR-deDuster with other conventional cyclones in terms of collection efficiency and pressure drop. The performance of MR-deDuster was measured by its collection efficiency based on the particle size distribution of activated carbon. It was found that MR-deDuster is able to collect as high as 94\% of PM 10 which is high comparing with many other conventional cyclones. In addition, the pressure drop of the unit is relatively low compared to the other cyclones which highlight the ability of the unit to capture the fine particle at low pressure drop.
\end{abstract}

Keywords: Air pollution; cyclone efficiency; dust emission; multi-cyclones; pressure drop

\section{ABSTRAK}

Sejenis konfigurasi reka bentuk siklon baru yang dikenali sebagai MR-deDuster yang mengandungi pelbagai siklon, telah dibangunkan. Suatu kajian teori telah dijalankan untuk menilai dan meramalkan prestasi MR-deDuster. Dalam kertas ini, suatu kajian perbandingan telah dijalankan untuk mengkaji prestasi MR-deDuster dengan siklon konvensional lain daripada segi kecekapan pungutan dan kejatuhan tekanan. Prestasi MR-deDuster diukur melalui kecekapan kutipan berdasarkan agihan saiz zarah karbon diaktifkan. Didapati bahawa MR-deDuster mampu untuk mengumpul seting gi $94 \%$ $P M_{10}$ jika dibandingkan dengan siklon konvensional lain. Di samping itu, penurunan tekanan bagi unit ini adalah agak rendah berbanding siklon lain yang menyerlahkan keupayaan unit untuk menangkap zarah halus pada tekanan rendah.

Kata kunci: Kecekapan siklon; pancaran habuk; pelbagai siklon; pencemaran udara; penurunan tekanan

\section{INTRODUCTION}

Cyclone is one of the most widely used dust separator in many industries due to its advantages of relative simplicity to fabricate, low cost to operate and good adaptability to extremely harsh conditions. The unit plays an important role in removing industrial dust emission (Azadi 2012). In addition, cyclone separators are simple to construct, easy to operate, with low capital and maintaining costs. Sometimes, cyclone is the only viable economical gas-solid separator for high temperature and pressure application (Rashid et al. 2013). Two most important characteristics in cyclone design are the collection efficiency and pressure drop that strongly influenced by the inlet particle concentration and the flue gas velocity (Hoffmann \& Stein 2007; Shepherd \& Lapple 1939). To date, a considerable number of experimental investigations have been performed either on laboratory or industrial scale cyclone separators for better prediction on the performances of cyclone (Norelyza \& Rashid 2013).

Bhatia and Cheremisinoff (1993) studied the effect of cone opening size of a cyclone and found that the pressure drop decreases slightly with increased in the cone size opening. Rongbiao et al. (2001) observed the effect of cone dimension on cyclone performance and suggested that gas flow rate influenced the efficiency of a cyclone and cone size has significantly impact on collection efficiency. Lippmann and Chan (1974) evaluated three different sizes of cyclones and found that the collection efficiency of the cyclones decreases with increasing dust concentration. Youngmin et al. (2000) developed an auxiliary device named post cyclone $(\mathrm{PoC})$ to reduce the emission of fines from the exhaust of reverse flow cyclones and demonstrated that the PoC increases the overall efficiency of the cyclone by 2-20\%. Wanga et al. (2010) installed an inner cylinder into a cyclone and able to increase the collection efficiency by $8 \%$ higher than the conventional cyclone at the gas inlet velocities ranged $12-26 \mathrm{~m} / \mathrm{s}$.

Although, studies to improve the performance of cyclone are reported, the unit is often regarded as a pre-cleaner device due to its low efficiency in capturing dust especially the finer size fraction. To overcome the problem, a number of small and high-efficiency cyclones which are installed in one unit known as multi-cyclone were introduced. Multi-cyclone consists of a quantity of collecting tube assemblies, each of which is an individual centrifugal dust collector. As illustrated, dust laden gas enters the top of the collecting tube through the inlet guide vanes. These vanes impart a smooth, fast spiral to the gas, 
setting up a highly centrifugal action to achieve higher collection efficiencies as well as to avoid rapid increase of pressure drop (Theodore 2008; Theodore \& Buonicore 1988). Multi-cyclones unit generally more efficient and manage to attain as high as $90 \%$ collection efficiency for dust with 5-10 $\mu \mathrm{m}$ size within a pressure drop of 2-6 inches water (Madhumita et al. 1998; Stairmand 1951). However, the ability of a multi-cyclone in capturing fine particulate size fraction is also limited and studies are focusing towards this development.

In our previous paper, we reported a new type of multi-cyclones known as MR-deDuster where its theoretical performance had been evaluated (Norelyza et al. 2014). The aim of this paper was to compare the performances of the newly developed MR-deDuster with other conventional cyclone/multi-cyclones in terms of collection efficiency and pressure drop, which are the main performance indicators of a cyclone separator.

\section{MATERIALS AND METHODS}

\section{COLLECTION EFFICIENCY OF MR-DEDUSTER}

The cut diameter $\left(d_{p c}\right)$ is a semi-empirical relationship developed by Lapple (1951) which referred to the size (diameter) of dust collected at 50\% efficiency. The $d_{p c}$ is a convenient method in expressing the efficiency of a dust control device, which is presented by (1):

$$
d_{p c}=\left[\frac{9 \mu W}{2 \pi N_{e}\left(\rho_{p}-\rho_{g}\right)}\right]^{1 / 2},
$$

where, $\mu$ is the gas viscosity $\left(\mathrm{kg} / \mathrm{m}^{3}\right), W$ is the maximum radial distance travel by a particulate $(\mathrm{m}), N_{\rho}$ is the number of effective turns, $V_{i}$ is the gas inlet velocity $(\mathrm{m} / \mathrm{s}), \rho_{g}$ is the density of gas $\left(\mathrm{kg} / \mathrm{m}^{3}\right)$ and $\rho_{p}$ is the density of dust $\left(\mathrm{kg} / \mathrm{m}^{3}\right)$. The value of $W$ is not directly obtain in case of a multicyclone design. Thus, a modification of Stairmand cyclone dimension with tangential entry that based on the same hydraulic diameter of axial and tangential entry was used to solve for $W$. Equations (2) and (3) are the tangential entry dimensions of a cyclone introduced by Stairmand (1951):

$$
\begin{aligned}
& D=\frac{W}{0.375} . \\
& D=\frac{H}{0.75},
\end{aligned}
$$

where, $W$ is the width of tangential entry $(\mathrm{m}), H$ is the height of tangential entry $(\mathrm{m})$ and $D$ is the diameter of cyclone body (m). Substitution of (2) into (3), will produce (4) as follows:

$$
H=2 W \text {. }
$$

The hydraulic diameter $\left(D_{H}\right)$ of tangential entry is referred to the $W$ and $H$ values as shown in (5),

$$
D_{H}=\frac{2 H W}{H+W} .
$$

Meanwhile, the hydraulic diameter $\left(D_{H}\right)$ of axial entry is referred to the $D$ and $D_{e}$ values as shown in (6),

$$
D_{H}=D-D_{e},
$$

where, $D$ is the diameter of the body of the cyclone $(\mathrm{m})$ and $D_{e}$ is the diameter of the vortex finder $(\mathrm{m})$. Substitution of (4) and (5) into (6) will produce (7) as shown below,

$$
W=\frac{3}{4}\left(D-D_{e}\right)
$$

Finally, substitution of (7) into (1) will generate the equation of cut diameter for axial entry as shown in (8),

$$
d_{p c}=\left[\frac{27 \mu\left(D-D_{e}\right)}{8 \pi N_{e} V_{i}\left(\rho_{p}-\rho_{g}\right)}\right]^{1 / 2} .
$$

Table 1 presents the assumptions and parameters used in the calculation of the collection efficiency of MRdeDuster. The collection efficiency was predicted using the particle size distribution of activated carbon.

TABLE 1. Cyclone parameters and operating conditions

\begin{tabular}{ll}
\hline Operating condition & Value \\
\hline Miniature cyclone diameter, $D(\mathrm{~m})$ & 0.105 \\
Vortex finder diameter, $D_{e}(\mathrm{~m})$ & 0.089 \\
Inlet velocity, $V_{i}(\mathrm{~m} / \mathrm{s})$ & 15 \\
Temperature, $T(\mathrm{~K})$ & 473 \\
Pressure, $P(\mathrm{~atm})$ & 1 \\
Particle dust density, $\rho_{p}\left(\mathrm{~kg} / \mathrm{m}^{3}\right)$ & 1000 \\
Flue gas density, $\rho_{p}\left(\mathrm{~kg} / \mathrm{m}^{3}\right)$ & 0.7448 \\
Flue gas viscosity, $\mu(\mathrm{kg} / \mathrm{hr} . \mathrm{m})$ & 0.093 \\
Number of effective turns, $N_{e}$ & 5 \\
\hline
\end{tabular}

The overall collection efficiency of MR-deDuster was predicted using Lapple approach as shown by (9) and (10),

$$
\begin{aligned}
& \eta_{j}=\frac{1}{1+\left(d_{p c} / d_{p j}\right)^{2}} . \\
& \eta_{o}=\sum \eta_{j} m_{j},
\end{aligned}
$$

where, $\eta_{j}$ is collection efficiency for the $j$ th particle size range, $d_{p j}$ is the characteristic diameter of $j$ th particle size range, $\eta_{o}^{p j}$ is the overall collection efficiency and $m_{j}$ is the mass fraction of particulate size range. 


\section{PRESSURE DROP OF MR-DEDUSTER}

Benitez (1992) approach was used in determining the pressure drop of MR-deDuster as shown in (11),

$$
\Delta P=\frac{N_{H} \rho_{g} Q^{2}}{2 K_{a}^{2} K_{b}^{2} D^{4}},
$$

where $N_{H}$ is a constant which depends on cyclone configuration $\left(N_{H}=6.125\right), \rho_{g}$ is the density gas $\left(\mathrm{kg} / \mathrm{m}^{3}\right)$, $Q$ is the flow rate of gas $\left(\mathrm{m}^{3} / \mathrm{s}\right), K_{a}$ and $K_{b}$ are configuration ratio (for Stairmand cyclone dimension, $K_{a}=0.75$ and $K_{b}=$ $0.375), n$ is the number of miniature cyclones in multicyclones and $D$ is the diameter of the cyclone body $(\mathrm{m})$.

The determination of pressure drop using Benitez approach strongly dependent on the relation of the number of miniature cyclones in a multi-cyclone, $n$ and the volumetric flow rate of flue gas, $\mathrm{Q}$ as in (12);

$$
Q=n V_{i} A,
$$

where, $Q$ is the volumetric air flow rate $\left(\mathrm{m}^{3} / \mathrm{s}\right), n$ is the number of miniature cyclones in multi-cyclones, $V_{i}$ is the gas inlet velocity $(\mathrm{m} / \mathrm{s})$ and $A$ is the effective area of gas entry for a miniature cyclone $\left(\mathrm{m}^{2}\right)$. The range of gas flow rates used in the study is based on a typical air volumetric flow rates from a selected local industry.

\section{RESULTS AND DISCUSSION}

\section{PARTICULATE COLLECTION EFFICIENCIES OF MR-DEDUSTER}

The MR-deDuster is constructed with a small body diameter and high body length miniature cyclones. The cut-diameter or $d_{p c}$ that is size of particulate collected with $50 \%$ efficiencies was used in defining efficiencies of MR-deDuster. The theoretical $d_{p c}$ of the unit was found to $2.4 \mu \mathrm{m}$, which illustrates the ability of MR-deDuster in capturing fine particulate size fraction (Norelyza et al. 2014).

Figure 1 presents the collection efficiency of MR-deDuster based on activated carbon particle size distribution which showed that the MR-deDuster is able to collect more than $60 \%$ particulate within the $5 \mu \mathrm{m}$ size range. The figure also showed that the MR-deDuster able to collect as high as $94 \%$ of particulates equal or less than $10 \mu \mathrm{m}$ in size. The small body size diameter of the MR-deDuster helps to increase its collection efficiency particularly the fine particulates size fractions.

\section{COMPARATIVE COLLECTION EFFICIENCY OF MR-DEDUSTER}

The collection efficiency and pressure drop resulting from this model were compared with the cyclone/multi-cyclone of different models, for example, Leith and Licth model (Coker 1993; Leith \& Licht 1996; Licht \& Koch 1977), Barth model (Bohnet et al. 1997), Mothes model (Mothes \& Löffler 1988), Lorenz model (Lorenz 1994), CFC (Wanga

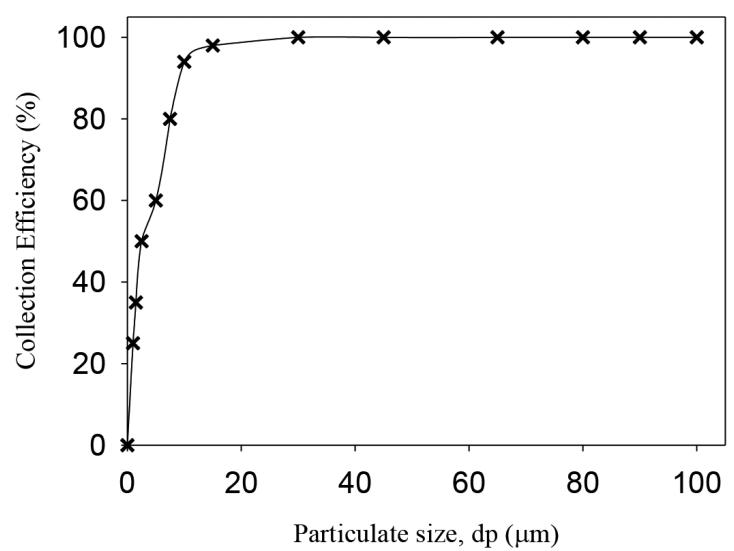

FIGURE 1. Collection efficiency of MR-deDuster on activated carbon

et al. 2010), DIII model (Wang et al. 1990), Ideal-laminar cyclonic flow model (Benitez 1992), turbulent cyclonic flow model (Benitez 1992), not ribbed-CFD, rib pitch to cyclone diameter ratio $(\mathrm{P} / \mathrm{D})=1.5-\mathrm{CFD}, \mathrm{P} / \mathrm{D}=1-\mathrm{CFD}$ Ideal (Farahani et al. 2011) and Karagoz model (Avci \& Karagoz 2003). The data of collection efficiency and pressure drop were taken from the descriptions of the individual model found in literatures. All these models used different assumptions or operating parameters to enhance the performance of their proposed model. The collection efficiency of MR-deDuster was based on the cut diameter and the particles size distribution of activated carbon. While the total separation efficiency of Mothes model was calculated with the particle mass flow which leaves the cyclone through the vortex finder and the mass flow entering the cyclone. In the case of $\mathrm{CFC}$ and DIII model cyclone, the total collection efficiency were measured by varying the gas inlet velocity from 12 to $26 \mathrm{~m} / \mathrm{s}$.

Figure 2 presents a comparison of fractional collection efficiency of various cyclone models based on their respective abilities of capturing particles less or equal to $10 \mu \mathrm{m}$ in size which showed that the performance of MR-deDuster is comparable or higher than most available models. As depicted in the figure, the MR-deDuster is able to collect as high as $94 \%$ of the $10 \mu \mathrm{m}$ size particle compared with other conventional cyclones. Thus, the unit can be utilised as the main air cleaner without having to consider a more efficient and expensive air pollution control system.

\section{PRESSURE DROP PREDICTION OF MR-DEDUSTER}

Pressure drop is one of the most element in designing a cyclone dependent on the configurations of the cyclone as well as the inlet particle concentration and volumetric air flow rate. Generally, the collection efficiency increases with increasing particle concentration, but the effect is more obvious in lower gas velocities. Typically, collection efficiency of a cyclone increases with pressure drop, which has a direct impact on the operating cost that requires a high suction fan to drive the flue gas through the cyclone system. 


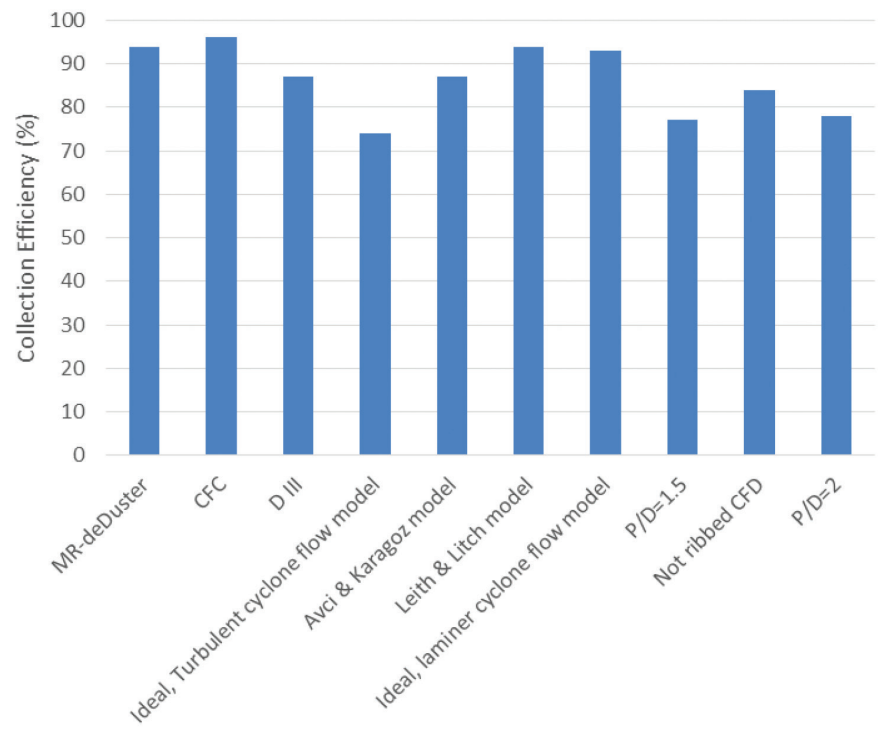

FIGURE 2. Fractional collection Efficiency of different cyclones on particles with smaller or equal to $10 \mu \mathrm{m}$ in size

Figure 3 presents the comparison of pressure drops of various cyclone models in terms of inlet air flow rates which showed that the pressure drop of MR-deDuster is steadily increased with air flow rates compared to others. In addition, the predicted pressure drop of MR-deDuster was found to be the lowest among the other models, which indicates its potentiality of reducing operational cost when put in service as compared with other cyclones. A multicyclones system such as MR-deDuster is able to obtain high collection efficiency at a much lower pressure drop than conventional single cyclone.

Benitez (1992) stated that the pressure drop of a multi-cyclones is closely related to the number of miniature cyclones. In fact, the equation used in predicting the pressure drop of MR-deDuster is dependent on the number of miniature cyclones and air volumetric flow rates. Interestingly, the pressure drop of MR-deDuster can be maintained at a desired value by merely increase the number of miniature cyclones in the compartment. Figure 4 shows the number of miniature cyclones MR-deDuster is linearly correlated with the air volumetric flow rates without jeopardizing its pressure drop. Thus, the MRdeDuster can be catergorized as an efficient with low pressure drop dust collector.

\section{CONCLUSION}

A comparison study was made to evaluate the performance of a newly developed MR-deDuster in terms of collection efficiency and pressure drop. The study illustrates that MR-deDuster is able to collect as high as $94 \%$ of particles of less or equal to $10 \mu \mathrm{m}$ in size, which is comparatively

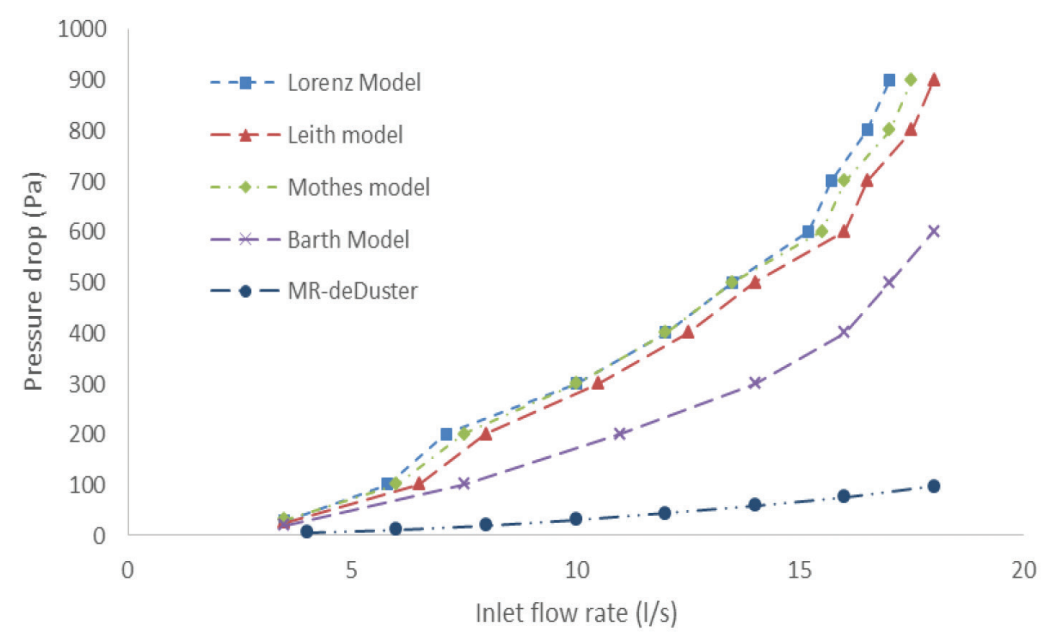

FIGURE 3. Comparison of pressure drop of various cyclones in terms of inlet air flow rates 


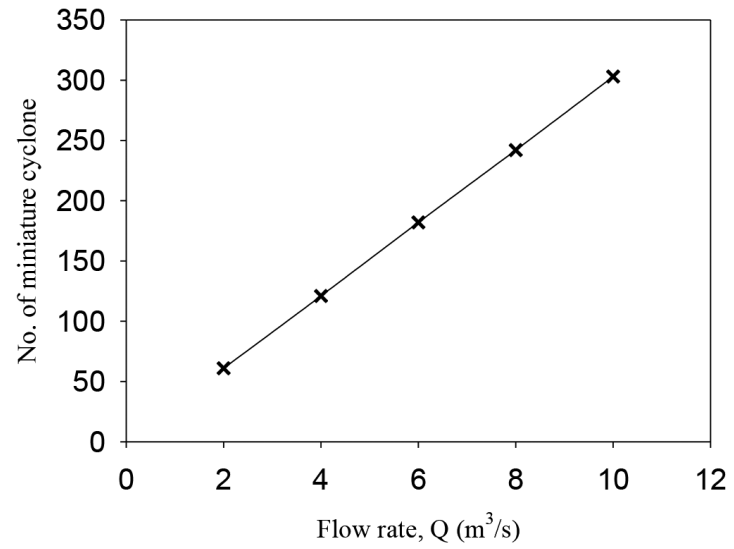

FIGURE 4. Number of MR-deDuster miniature cyclone for different air flow rates

higher than most conventional cyclones. The study also showed that the predicted pressure drop of MR-deDuster was the lowest compared with other conventional cyclones suggesting of its ability reducing the operational cost of the system. The system can be made to operate with any air volumetric flow rates without jeopardizing its pressure drop. The performance of MR-deDuster will further be scrutinized experimentally.

\section{ACKNOWLEDGMENTS}

The authors gratefully acknowledged the financial support for scientific research from the Malaysia-Japan International Institute of Technology (MJIT), UTM Kuala Lumpur.

\section{REFERENCES}

Avci, A. \& Karagoz, I. 2003. Effects of flow and geometrical parameters on the collection efficiency in cyclone separators. J. Aerosol. Sci. 34: 937-955.

Azadi, M. 2012. An analytical study of the effect of inlet velocity on the cyclone performance using mathematical models. Powder Technology 217: 121-127.

Benitez, J. 1992. Process Engineering and Design for Air Pollution Control. New Jersey: Prentice Hall.

Bhatia, M.U.\& Cheremisinoff, P.N. 1993. Pollution control and Design for Industry. New York: Marcel Dekker.

Bohnet, M., Gottschalk, O. \& Morweiser, M. 1997. Modern design of aerocyclones. Adv. Powder Technol. 8(2): 137-161.

Coker, A.K. 1993. Understand cyclone design. Chem. Eng. Prog. 28: 51-55.

Farahani, N.S.M., Tahmasbi, V., Safikhani, H. \& Abbasi,A. 2011. Effects of ribs on flow pattern and performance of cyclone separator. Engineering Application of Computional Fluid Dynamics 5(2): 180-187.

Hoffmann, A.C. \& Stein, L.E. 2007. Gas Cyclones and Swirl Tubes Principles, Design and Operation. New York: Springer.

Lapple, C.E. 1951. Process use many collector types. Chemical Engineering 58(5): 175-183.

Leith, D. \& Licht, W. 1996. The Collection Efficiency of Cyclone Type Particle Collectors: A New Theoretical Approach. AIChE Symp. Ser. Air Pollut. Control.
Licht, W. \& Koch, W.H. 1977. New design approach boosts cyclone efficiency. Chem. Eng. Prog. 7: 80.

Lippmann, M. \& Chan, T.L. 1974. Calibration of dual-inlet cyclones for 'respirable' mass sampling. American Industrial Hygiene Association Journal 35(4): 189-200.

Lorenz, T. 1994. Heissgasentstaubung mit zyklonen. Düsseldorf, Germany: VDI-Fortschrittsberichte.

Madhumita, B.R., Pouwel, E.L., Hoffman, A.C., Plomp, A. \& Beumer, M.I.L. 1998. Improving the removal efificiency of industrial-scale cyclones for particles smaller than five micron. International Journal of Mineral Processing 53: 39-47.

Mothes, H. \& Löffler, F. 1988. Prediction of particle removal in cyclone separators. Int. Chem. Eng. 28(2): 51-55.

Norelyza,H. \& Rashid, M. 2013. Performance of MR-deDuster: A case study of a palm oil mill plant. Advance Materials Research 664: 133-137.

Norelyza, H., Rashid, M., Hajar, S. \& Nurnadia, A. 2014. MRdeDuster: A dust emission separator in air pollution control Jurnal Teknologi (Sciences \& Engineering) 58: 85-88.

Rashid, M., Chong, W.C., Ramli, M., Zainura, Z.N. \& Norruwaida, J. 2013. Evaluation of particulate emission from a palm oil mill boiler. Sains Malaysiana 42(9): 1289-1292.

Rongbiao, X., Park, S.H. \& Lee, K.W. 2001. Effects of cone dimension on cyclone performance. Aerosol Science 32: 549-561.

Shepherd, C. \& Lapple, C. 1939. Flow pattern and pressure drop. Ind. and Eng. Chem. 31: 972-984.

Stairmand, C.J. 1951. The design and performance of cyclone separators. Transactions of Industrial Chemical Engineers 29: 356-383.

Theodore, L. 2008. Air Pollution Control Equipment Calculation. New Jersey: John Wiley \& Sons.

Theodore, L. \& Buonicore, A.J. 1988. Air Pollution Control Equipment. Florida: CRC Press.

Wang, H.B., Bao, Y.L., Zhao, M.Q., Yang, L.D. \& Yu, H.B 1990. Analogy simulation of the properties of a circulating fluidized-bed boiler high-temperature cyclone separator. $J$. Engineering for Thermal Energy and Power 5: 14-20.

Wanga, W., Zhang, P., Wang, L., Chen, G., Li, J. \& Li, X. 2010 Structure and performance of the circumfluent cyclone. Powder Technology 200: 158-163.

Youngmin, J., Tien, C. \& Ray, M.B. 2000. Development of a post cyclone to improve the efficiency of reverse flow cyclones. Powder Technology 113: 97-108.

Air Resources Research Laboratory

Malaysia-Japan International Institute of Technology

54100 UTM Kuala Lumpur

Malaysia

*Corresponding author; email: rashidyusof.kl@utm.my

Received: 20 August 2014

Accepted: 7 November 2014 